https://doi.org/10.48009/1_iis_2010_460-466

\title{
THE IMPACT OF WEB BROWSING ON CLASSROOM LEARNING PERFORMANCE
}

\author{
Han Li, Minnesota State University,li@ mnstate.edu \\ Yingjin Cui, Virginia State University, ycui@vsu.edu \\ Xue Bai, Virginia State University, xbai@ vsu.edu \\ Steve Davis, Clemson University, davis@ clemson.edu
}

\begin{abstract}
In a growing number of classes, students have internet access through laptop or laboratory computers. Internet access could enhance student learning by allowing them to read online course materials provided by the instructor plus other material relevant to the course. However, students may be distracted from the class by surfing the Internet, chatting online, checking emails, and so on. Therefore, one may wonder, on balance, whether or not Internet access is beneficial to learning. This study employed a controlled experiment to investigate how Internet access influences classroom learning. Browsing non-class web sites during class time had a detrimental effect on students' learning, but student access to class-related web sites improved it. Therefore instructors should consider using control mechanisms to block access to nonclass web sites during class lectures. Students should be encouraged to browse through slides while listening to the lecture.
\end{abstract}

Keywords: Internet Access, Student Learning, Computer-Based Instruction

\section{INTRODUCTION}

Internet Access is altering both teaching and learning processes [5,6,8]. Many classrooms are now being equipped with wireless Internet access for student laptops, or laboratory computers having internet access $[2,3,14,18]$. Yet few studies have investigated the impact of Internet access on the student learning process $[9,20]$. The Internet could support student learning or it could be a distraction. Internet access could enhance student learning by allowing them to read online course materials provided by the instructor plus other material relevant to the course. However, students may be distracted from the class by surfing the Internet, chatting online, checking emails, and so on. Jeffrey Young [21] described this potential problem. " .... the student will direct about as much attention to the front of room as airline

Volume XI, No. 1, 2010 passengers do to a flight attendant reviewing safety information." Many faculty members control Internet access in classrooms, even though there is little research to support such an action. It could help educators to know whether Internet access is worthwhile on balance, and whether controlling access could be beneficial.

\section{THEORETICAL FRAMEWORK AND RESEARCH HYPOTHESES}

Easy access to computers and network in a computer lab increases the opportunities for students to multitask. While listening to lectures, students may perform some computer activities such as browsing course materials or non-class related Internet materials. According to Lang [12], because a person's ability to process information is limited, such split attention among multiple tasks is very likely to influence the learning outcome and satisfaction of students. Our study employs Lang's limited capacity model. In the subsections below, we will review this model and propose our research hypotheses.

\section{Limited Capacity Model}

The limited capacity model has two assumptions [12]. First, people are information processors. Second, a person's processing capacity or mental resources are limited. The information processing consists of three sub processes: (a) encoding; (b) storage; and (c) retrieval.

Encoding involves selectively capturing information in the environment in the sensory store and transferring information gathered in sensory store into working memory [12]. Working memory is short-lived and has limited capacity, which can hold a few information cues at one time. Only a fraction of information in the environment could be encoded and stored in the working memory. What information gets encoded is driven by both automatic and controlled processes. Under controlled process, information captured reflects a person's goals about what specific information to acquire. The automatic selection processes are unconscious and could be 
activated when there are changes or unexpected occurrence in the environment $[10,17]$.

Information in the working memory could easily be lost in a very short period and needs to be further transferred to longer term memory through a storage subprocess. Long-term memory is inactive but has unlimited storing capacity. Storage subprocess occurs when the information in the working memory could be connected to other related memory by associations [12]. The new information is more readily stored in the long-term memory when the new information has more association with the old information.

Retrieval is the subprocess of searching the long-term memory through associative links and reactivating some information in working memory. Information that has more associative links to other information is more likely to be stored and retrieved.

\section{Student Learning Outcomes}

The three subprocesses in Lang's model are tied closely to students' learning outcomes in the classroom. Encoding is necessary for a message to be selected into working memory and the storage through associative links with existing memory is necessary for the stored information to be successfully recalled later. Some lecture content may be encoded but less well stored in the long-term memory. As a result, a student may have a mental representation of those contents in his or her longterm memory and could recognize the information if the information is provided as one of the choices among others. However, the student may be unable to recall the content without sufficient number of cues or associative links to retrieve the content from the long-term memory.

Different measures of memory have been suggested to measure how well information is encoded and stored [12]. A recognition test provides a multitude of cues to help subjects identify items that they have been exposed to and is a good measure on whether a specific piece of information is encoded. One example of a recognition test is a multiple choice question. Cued recall provides some cues to subjects to help them retrieve the information from the memory and could be used as a measure of how well the information is stored in the long-term memory. Fill-in-the-blank questions are one type of cued recall test that could measure how thoroughly lecture content is stored in the long-term memory of students. Therefore, in this study, we use multiple choice questions and fill-in-the-blank questions to measure the learning outcome of students.

\section{Impact of Access to Non-class Web Sites}

The effectiveness of encoding a message is constrained by the amount of processing resources allocated for processing that message and the capacity of the working memory. Encoding could be enhanced by expanding the working memory of a message recipient. Research on cognitive load suggests that people use separate memory channels for auditory and visual information and that more working memory will be available when a dual presentation mode is used [15]. A typical college lecture to students having computers consists of two redundant streams of information conveyed simultaneously in both auditory and visual modes. For example, students could view lecture-related slides while listening to the verbal elaboration from the instructor. On the other hand, the encoding is compromised when fewer resources are allocated than needed for encoding a given message [12]. When students split their attention between listening to the lecture and browsing non-class web sites, they primarily use the audio channel to capture course content and waste the visual working memory on web content irrelevant to the class materials. In addition, students would experience increased cognitive load due to processing two unrelated messages, those from the lecture and the irrelevant material on the computer. This extra load on students' limited processing resources leads us to hypothesize that

H1: Access to non-class-related web sites reduces the effectiveness of encoding (or recognizing) lecture content.

Encoding and storage are closely related. An information cue must be encoded first before it has a chance to be stored in the long-term memory and recalled later. Lecture content that never enters the working memory will also be missing in the longterm memory. Access to non-class web sites is expected to indirectly reduce the amount of lecture information stored in the long-term memory through disrupting the encoding of the lecture content. Therefore, 
$\mathrm{H} 2$ : The encoding of lecture content is positively related to the recall of that content.

\section{Impact of Access to Class-Related Web sites}

While listening to the lecture, students may use computers in front of them to access class-related material such as PowerPoint slides. The dual presentation model involves a split of mental processing resources between auditory and visual information. Students' active browsing on a computer of class-related material may change the proportion of mental resources allocated to process auditory and visual information. Students may allocate more resources to process visual information and improve the storage of lecture content in the long-term memory. Previous studies have shown that information captured in textual format is better recalled than auditory information [16,19]. Therefore,

H3: Browsing lecture-relevant material while listening to the lecture improves the long-term storage and recall of lecture content.

\section{RESEARCH METHODOLOGY}

Study Design and Procedures
The experimental environment was a computer lab controlled by Classroom Control and Instruction System (CCIS) software. Students did not have their own laptop computers. CCIS allows an instructor to interact with their students either on an individual basis or as a group. Through CCIS, an instructor could send individual or group messages to students in pop-up windows. CCIS also allows monitoring and control of a network of computers from a central location, such as selectively or completely restricting Internet access.

In our experimental settings, we randomly assigned subjects to three groups. In group 1, computers are locked and display only the message "Watch the video lecture. You are NOT allowed to use the Internet or any other application." The pre-recorded video lecture consisted of PowerPoint slides with instructor audio monologue. In group 2, participants were prompted by a CCIS message to open the browser window. When they opened the browser window, the browser window automatically displayed a link to the PowerPoint slide file that supported the lecture. They were encouraged to navigate through slides while listening to the video lecture but were not allowed access to any non-class web sites. In group 3, participants were asked to listen to the video lecture and were allowed to browse any web sites. The experimental settings are summarized as follows:

Table 1. Assignment of Students to Experimental Groups

\begin{tabular}{lccc}
\hline & Group 1 & Group 2 & Group 3 \\
$\begin{array}{l}\text { Access to class-related web site } \\
\text { (PowerPoint slides) }\end{array}$ & No & Yes & No* \\
Access to non-class web sites & No & No & Yes \\
\hline * PowerPoint file web site is not announced to Group 3. & &
\end{tabular}

A pilot study was conducted in two summer courses at an Eastern U.S. university in 2008. The purpose was to refine the experimental procedure and survey measurement. The final experiment was administered to students in five sections of a lower division introduction to information systems course in fall 2008.

Volume XI, No. 1, 2010
At the beginning of the experiment, all participants were requested to participate in a study on education technology that included a short quiz and a survey at the end of a prerecorded video lecture. Then groupspecific instructions were displayed on each computer screen, as follows:

Group 1: 
Watch the video lectures. You are NOT allowed to use the Internet and any applications and chat with others.

\section{Group 2:}

Please open Internet Browser and click the link on the home page to access PowerPoint files related to the video lectures. You are encouraged to navigate through slides while listening to the corresponding video lecture.

\section{Group 3:}

Listen to the video lectures. You are allowed to browse the Internet at your own will while listening to the lectures. But NO chatting is allowed.

After listening to the video lecture, students were provided a link to the online survey and invited to fill out the survey including 20 quiz questions on a voluntary basis. A total of 181 students participated in the study. Among them, 47 responses in Group 2 were not usable due to network connection issues, which prevent subjects from successfully browsing the PowerPoint slides accompanying the video lecture. Therefore, a total of 134 valid responses were received. The experiment took approximately one hour to complete.

\section{Variable Measurement}

The three groups (Table 1) were coded into two dummy variables: access to class-related web site and access to non-class web sites. Group 1 was used as the reference group and assigned zero for both dummy coded variables. Group 2 was assigned 1 for access to class-related web site variable and 0 for access to non-class web sites variable. Group 3 was assigned 0 for access to class-related web site variable and 1 for access to non-class web sites variable.

The learning outcome was assessed using quiz results. The quiz consisted of ten multiple choice questions and ten fill-in-the-blank questions. Scores on the multiple choice test were used to assess the effectiveness of encoding lecture content. Scores on the fill-in-the-blank test were used to gauge the effectiveness of recall.

Volume XI, No. 1, 2010
Two questions checked whether students in groups having access to slides or to non-class web sites actually browsed the slides or non-class web sites more than students without access. The questions are: 1) "Did you read the PowerPoint slides accompanying the video lecture on the Web while listening to the video lecture given today?" and 2) "Did you visit any web sites that are NOT related to the video lecture while listening to the video lecture given today?"

\section{Data Analysis}

For group 1, we coded "no" for all student responses to the "browsing non-class websites" question because access was blocked. We employed two ANOVA tests and Scheffe pairwise comparisons to compare group means for questions "reading the PowerPoint slides" and "browsing non-class web sites". For both questions, we found that students in groups having access to slides or to non-class web sites performed significantly more actual browsing of slides or non-class web sites.

We then used a partial least squares (PLS) technique to test the measurement model and research hypotheses because it does not assume a multivariate normal distribution and interval scales [4,7]. Our model consists of two binary dummy coded independent variables.

\section{Measurement Model}

We examined convergent validity, reliability and discriminant validity of three latent constructs before testing the hypotheses. Our measurement model demonstrates sound reliability and validity. The results of measurement model testing are available upon request.

\section{RESULTS}

Figure 1 compares the learning outcomes of the three groups based on the average number of correct multiple choice answers and fill-in-the-blank answers on the quiz. Students in groups 1 and 2 performed about the same on the multiple choice quiz and they outperformed those in group 3. For fill-in-the-blank questions, students in group 2 performed much better than students in the other two groups. Overall, group 2 outperformed the other two groups on both multiple choice and fill-in-the-blank tests. Most students in group 2 opened the class-related PowerPoint files 
while listening to the video lectures, which may have helped them perform better on a quiz than other groups. Group 3 performed worst on both multiple choice and fill-in-the-blank tests. Access to non-class web sites seemed to negatively influence a student learning effectiveness.

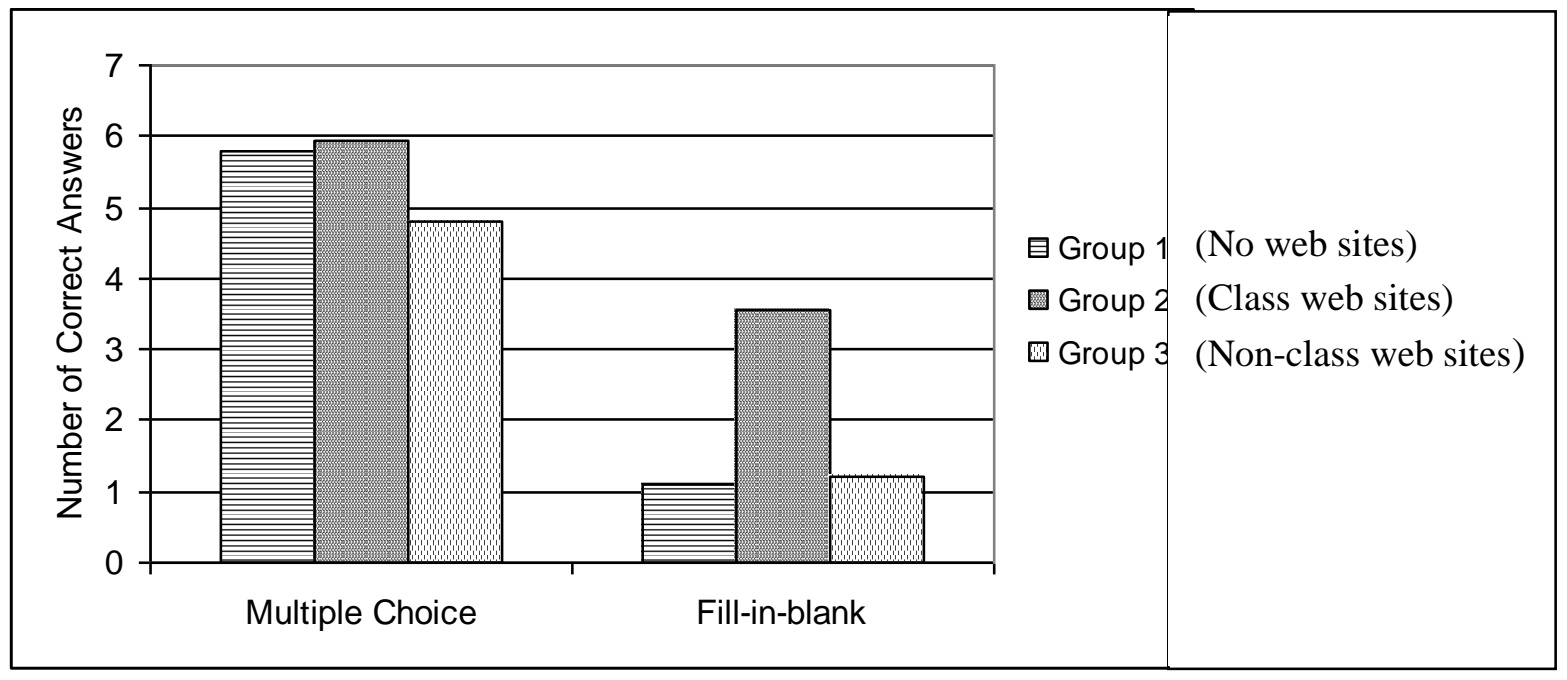

Figure 1. Comparison of learning outcomes of the three groups based on quiz results.

Figure 2 summarizes the results of testing the hypotheses. The model could explain $9.7 \%$ of the variance in the scores on multiple choice tests, and $34.2 \%$ of the variance in scores on fill-in-the-blank tests.

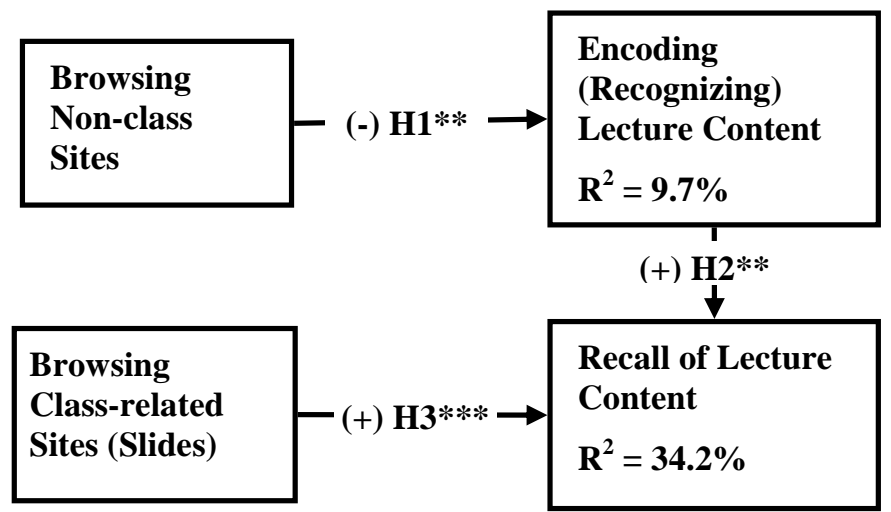

Figure 2. Results of testing hypotheses using PLS analysis, **p $<0.01, * * * p<0.001$ (two-tailed).

All research hypotheses were found to be statistically significant. Overall, the research model is well supported.

\section{Summary of Findings and Limitations}

Our findings suggest access to non-class web sites increases the cognitive load of students and reduces

Volume XI, No. 1, 2010 the mental resources allocated to encode the lecture content into working memory. As a result, students browsing non-class web sites could recognize fewer information cues in the lecture content than those deploying both auditory and visual sensory channels to capture the lecture content. On the other hand, when students use their computers to browse through class-related slides while listening to the lecture, they 
perform well in both encoding lecture materials and storing them in long term memory. Since they use both auditory and visual channels to capture lecture content, they are able to encode much more lecture material than those browsing non-class web sites. In addition, those browsing class-relevant slides are able to enhance the quality of stored lecture information in long-term memory and recall more lecture content than those only watching the video lecture or those browsing non-class web sites.

This study has some limitations. Based on college student subjects, research findings may not extend to very young children who have not developed sufficient vocabulary or reading skills. In this case, the extra benefit from access to class-related web sites may be weak or nonexistent. Future studies are needed to test the model on young children with different reading skills. We examined only two computer usage behaviors in a computer lab. Future studies could examine the effect of other computer usage behaviors such as online chatting and typing lecture notes, etc.

\section{CONCLUSIONS}

This paper applied the Limited Capacity Model [12] to understand the effects of in-class Internet access. Access to non-class web sites decreased the amount of information encoded into the short-term working memory, but access to class-related web sites (slides) facilitated the storage of lecture content in the longterm memory.

\section{REFERENCES}

[1] Adewunmi1, A., Rosenberg, C., Sun-Basorun3, A., Koo, S. Enhancing the In-Classroom Teaching/Learning Experience Using Wireless Technology. $33^{\text {rd }}$ ASEE/IEEE Frontiers in Education Conference, Boulder, Co., November 5-8. 2003.

[2] Anderson, R., VanDegrift, T., Wolfman, S. Yasuhara, K. Promoting Interaction in Large Classes with Computer-Mediated Fedback. Proceedings of Computer Support for Collaborative Learning. June 2003.

[3] Anderson, R., Simon, B., Wolfman, S., VanDegrift, T. \& Yasuhara, K. Experiences with a Tablet PC Based Lecture Presentation System in
Computer Science Courses. Proceedings of the SIGCSE Technical Symposium on Computer Science Education, Norfolk, VA, March 2004, p. 56-60.

[4] Bagozzi, R. P., Yi, Y. On the Evaluation of Structural Equation Models. Journal of the Academy of Marketing Science, 16(1): p. 74-94. 1988.

[5] Bartlow-Davis, K. Embracing Technological Advancement in the Classroom. Society for Technical Communication. Fall 2007.

[6] Campbell, P., Pargas, R. Laptop in the Classroom. SIGCSE Technical Symposium on Computer Science Education, Reno, Nevada, February 2003, p. 98-102.

[7] Chin, W. W., Marcolin, B. L., \& Newsted, P. R. A Partial Least Squares Latent Variable Modeling Approach For Measuring Interaction Effects: Results From A Monte Carlo Simulation Study And An Electronic Mail Adoption Study. Information Systems Research, 14(2): p. 189-217. 2003.

[8] Cuban, L. Oversold and Underused: Computers in the Classroom. Harward University Press, Cambridge, 2001.

[9] Foster, K. Are Classroom Computers Worthwhile? IEEE Spectrum, 39, February 2002. p. 60-60.

[10] Graham, F. K. Afterward: Pre-Attentive Processing and Passive and Active Attention. In P. J. Lang, R. F. Simons \& M. Balaban (Eds.), Attention and orienting: Sensory and motivational processes, Erlbaum, Hillsdale, NJ, p. 417-452. 1997.

[11] Green, S. G., Taber, T. D. The Effects Of Three Social Decision Schemes On Decision Group Process. Organizational Behaviour and Human Performance. 25: p. 97-106. 1980.

[12] Lang, A. The Limited Capacity Model Of Mediated Message Processing. Journal of Communication. 50(4): p. 46-70. 2000.

[13] Lau, V. C. S., Au, W. T., Ho, J. M. C. A Qualitative And Quantitative Review Of Antecedents Of Counterproductive Behavior In Organizations. Journal of Business and Psychology. 18(1): p. 73-99. 2003. 
[14] Moody, L. \& Schmidt, G. Going Wireless: The Emergence of Wireless Networks in Education. Journal of Computing Sciences in Colleges. 19(4): p. 151-158. 2004.

[15] Mousavi, S., Low, R., Sweller, J. Reducing Cognitive Load By Mixing Auditory And Visual Presentation Modes. Journal of Educational Psychology. 87(2): p. 319-334. 1995.

[16] Nasco, S. A., Bruner, G. C. Perceptions And Recall Of Advertising Content Presented On Mobile Handled Devices. Journal of Interactive Advertising. 7(2). 2007.

[17] Ohman, A. As Fast As The Blink Of An Eye: Evolutionary Preparedness For Preattentive Processing Of Threat. In P. J. Lang, R. F. Simons \& M. Balaban (Eds.), Attention And Orienting: Sensory And Motivational Processes. Erlbaum, Hillsdale, NJ. p. 165-184. 1997.

[18] Ryder, J. "Universal Computer Access for Students - a Classroom Experiment in Computer Science". Journal of Computing Sciences in Colleges. 15(5): p. 52-60. 2000.

[19] Sewell, H. E., Moore, R. L. Cartoon Embellishments in Informative Presentations. Educational Communication and Technology Journal. 28(1): p. 39-46. 1988.

[20] Shotsberger, P., Vetter, R. Teaching and Learning in the Wireless Classroom. IEEE Computer. 34: p. 110-111. 2001.

[21] Young, J. The Fight for Classroom Attention: Professor vs. Laptop. The Chronicle of Higher Education, 52(39): p. A27. 2006. 